\title{
Research and Design on the System of Wave energy of Seawater Desalination with Negative Pressure
}

\author{
Wang Chao \\ School of energy and power engineering \\ Wuhan University of Technology \\ Wuhan China \\ e-mail: 694446963@qq.com
}

\author{
Zheng Weigang \\ School of energy and power engineering \\ Wuhan University of Technology \\ Wuhan China \\ e-mail: zfeidiao@163.com
}

\begin{abstract}
Based on the marine drilling platform or the freshwater shortages of barren island that need to be developed, the paper proposes a new type of energy saving through the wave energy device to manufacture freshwater. The wave energy of the sea can be converted into the negative pressure of the system through the marine float, the intermediate transmission device and negative pressure device, and it can lower the temperature of evaporation and saturation of seawater that are to be desalinated, and reduce heat energy which is needed to evaporate seawater, so as to achieve the purpose of energy saving.First, this paper set up a thermodynamic model of the device, then the mathematical model of the whole system in the steady state according to each device in the system. Through the simulation, the relationship between freshwater yield of wave energy seawater desalination system of and the location of the sea shows that the device can be more efficient for seawater desalination and basically meet the needs of offshore drilling platform on water demand with good economic benefit and the energy-saving effect.
\end{abstract}

Keywords : wave energy; negative energy; energy conversion; desalination of sea water

\section{RESEARCH CONTENTS}

The average daily water offshore drilling platform amount determined through access to information and sampling methods, in order to determine the minimum water quantity; and to determine the structure of the system and stable working platform sea area near the seasonal correlation of natural factors (for example: wind speed, wave height, wave cycle).

According to the analysis of the survey results and data, calculate the water collection tank capacity requirements and reasonable low limit; rational design of the wave shape, determine the size, screening materials; reasonable arrangements for the design of negative pressure fresh water conversion device installation.

Considering the low limit, tank capacity and the wave body size data and consider all the loss and error to determine the volume of work, volume type vacuum pump of the selected materials, reasonable design of pipeline; determine the solar battery board size and calculating the daily generation capacity.

Calculating with data, the minimum driving force and power of the pump; the average travel by the wave force and wave average in single cycle.

Comprehensive analysis of the data, through the reasonable calculation and simulation design of negative pressure device is reasonable; and according to the minimum driving force and the parameter calculation of the intermediate transmission mechanism of stress wave, the design of efficient transmission device; considered reasonable for the solar energy device.

Through the Matlab analysis software for data analysis and simulation.

\section{INTRODUCTION}

In the freshwater resources are nowadays increasingly scarce, seawater desalination as a new technique for freshwater resources replacement, has been highly praised by many countries and institutions. But in the remote area such as remote islands and offshore oil drilling platform and big warships, due to the high input, high consumption, equipment complex reasons, resulting in seawater desalination technology is not widely used in production and living practice, therefore the development of a novel energy-efficient desalination device is imminent, this will vigorously promote the development of marine resources.

In recent years, research on seawater desalination gradually aroused the concern of researchers, and issues related to energy-efficient desalination has become a hot spot. Methods usually include seawater desalination by freezing method, electrodialysis, distillation, reverse osmosis. Evaporation is heated to a saturated seawater evaporation temperature, the method of water vapor through the reflux condenser to collect make water. Through the thermodynamic relations, in low-pressure environments, or saturated temperature decreased, the corrosion and scaling rate is slow, the desalination device has an extended life. In advocating energy-saving emission reduction policies in the background, a new device of energy producing freshwater through wave has important significance. According to the characteristics of offshore drilling platform near the sea, to design a device using wave energy producing fresh water desalination, establish mathematical model in the runtime system, realizes the simulation of steady-state system, aimed at improving the accuracy of simulation, research in different sea water output, optimize the performance of 
the system.

\section{WAVE ENERGY SEAWATER DESALINATION SYSTEM OF NEGATIVE PRESSURE TYPE}

Wave energy seawater desalination system is mainly used for the seawater desalination method for distillation. The device comprises: marine float, solar cell film, reciprocating follower, a negative pressure device, an evaporation tank has reflux condensation device. Figure 1 is the schematic diagram of negative pressure wave energy seawater desalination system.

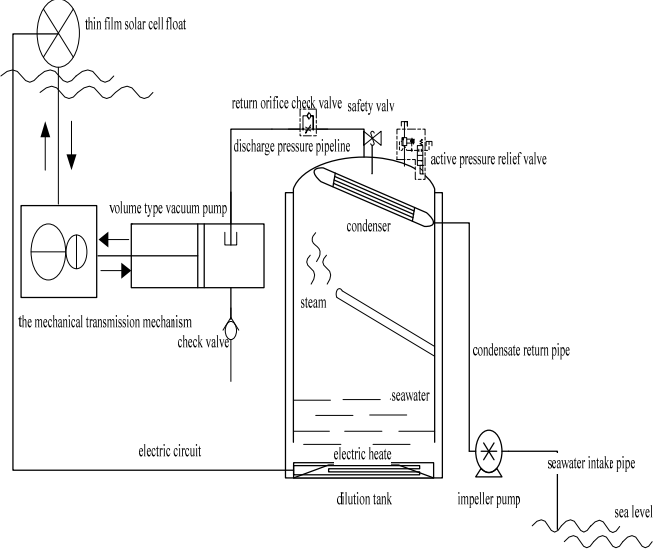

Figure . 1 Schematic diagram of negative pressure wave energy seawater desalination system

The system will wave can float through the reciprocating transmission mechanism, water pressure pump into the vacuum energy, making desalination device to heat requirements are reduced, and the top of the float paving thin film solar cell, wave energy conversion system -- negative pressure can be combined with the photoelectric conversion system, so that the pressure evaporation tank reaches a certain temperature saturated water vapor critical pressure, the water heated by electric heating device, so that the rapid vaporization of water, when the water vapor in the evaporator encountered in a reflux condensation collection device of liquefied, so as to achieve the purpose of producing fresh water. Figure 2 is a flow chart of the energy conversion system.

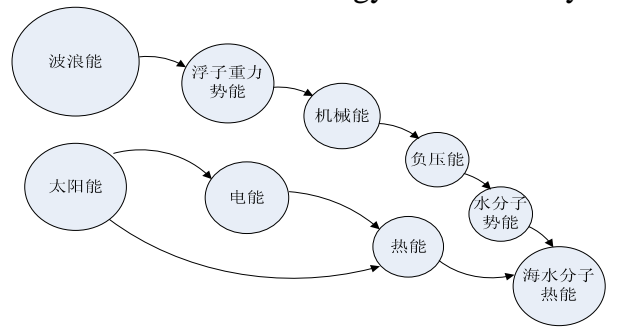

Figure 2 flow energy conversion system diagram

The system uses the wave energy and solar energy as the energy source, has the characteristics of simple structure, high evaporation efficiency, low operation cost and maintenance cost, and good environmental protection characteristics.

\section{DESALINATION PROCESS THERMODYNAMIC MODELING}

Through the analysis of marine conditions, selection of vacuum pump.Design of calibration pressure irrigation desalination in calculating evaporation temperature, sea, when the condenser water vapor meet top will be cooled into fresh water, so water desalination irrigation is the core device of the system. In order to study the desalination of seawater desalination system performance, established the mathematical model of seawater desalination process, thermodynamic model including the thermodynamic model and reflux condensation heating process.

The following mathematical model of seawater heating:

$Q=q_{s}\left(C_{s, P, 1} T_{s, 1}-C_{s, P, 2} T_{s, 2}\right)$

The above formula , $Q$ is The amount of heating water, $q_{s}$ is The mass flow of seawater, $C_{s, p, 1}$ is water heater of the specific heat at constant pressure, $C_{s, p, 2}$ is Seawater into the heater when the specific heat at constant pressure, $T_{s, 1}$ is the temperature of the sea when after the heater, ${ }^{T_{s, 2}}$ is the temperature of the sea when enter the heater.

The thermodynamic model of cooling process:

$Q_{C}=q_{c, n} \eta_{c, n}$

$Q_{c}=q_{a, c, 1} C_{p, s, c 1} T_{a, c, 1}-q_{a, c, 2} C_{p, s, c 2} T_{a, c, 2}$

$Q_{c}=K_{c} F_{C, 0} \Delta T_{m}$

\section{SIMULATION}

Simulation in Level 2 of the ocean conditions, wave height is 0.5 meters, angular frequency is $2.1 \mathrm{rad} / \mathrm{s}$, through the simulation of the seawater desalination system calibration pressure in different dilution tank produced under different water content.Figure 3 is the relation between pressure in resh water generator the and water yield.

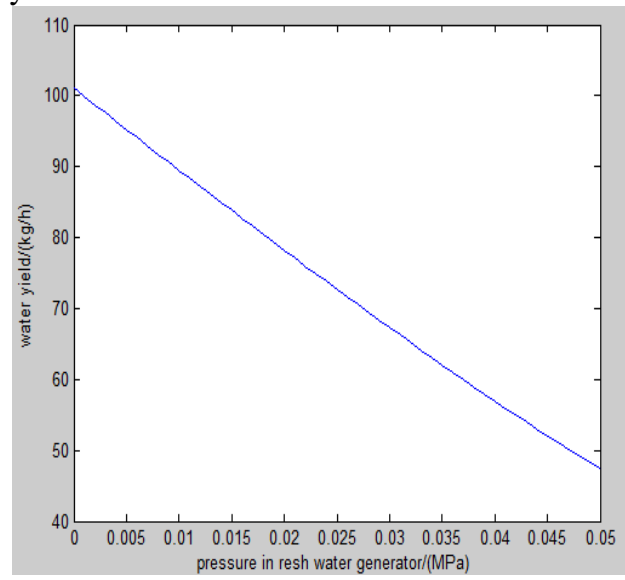


Figure 3 the relation between pressure in resh water generator the and water yield

\section{CONCLUSION}

Through the analysis of wave energy seawater desalination system, and established the mathematical model of system, and adopts the module method, the simulation system, the simulation structure with high accuracy. Studies show that the performance of the seawater desalination system is higher, can meet the needs of medium-sized drilling platform for fresh water, the energy conservation effect is obvious.

According to the country ' ' 12th Five-Year Plan ' ' in the energy-saving emission reduction policies, China will increase the development and utilization of renewable energy, the construction of a resource-saving, environment-friendly society. Using the device of wave energy producing fresh water to achieve the development and utilization of new energy, alleviate the exhaustion of non-renewable energy consumption. With good economic benefits, and social significance.

\section{REFERENCES}

[1] Song Baowei, Ding Wenjun and Mao Zhaoyong. "Conversion System of Ocean Buoys Based on Wave Energy”.journal of mechanical engineering. 2012,jun

[2] Ni Jing, Gu Jinhong, Shen Jian and Xu Wenqi."Modeling and thermal analysis of flash -- evaporation desalination system for ship ". Technology of water treatment. 2012 ,jan

[3] Wang Yongqing. "Thermodynamic analysis of combined steam-injected gas turbine and seawater desalination system”. Journal of engineering thermophysics. 2008, jun

[4]Sun Yeshan, tour jago, Ma Yujiu. "Research wave on-powered seawater desalination appliacations”.Renewable energy resources. 2007 apr

[5] Lin Runsheng, Ye Jiawei, Liu lin"Study on the application of floater's relative heaving motion in seawater desalination"guangdong shipbuilding. 2010.29 